
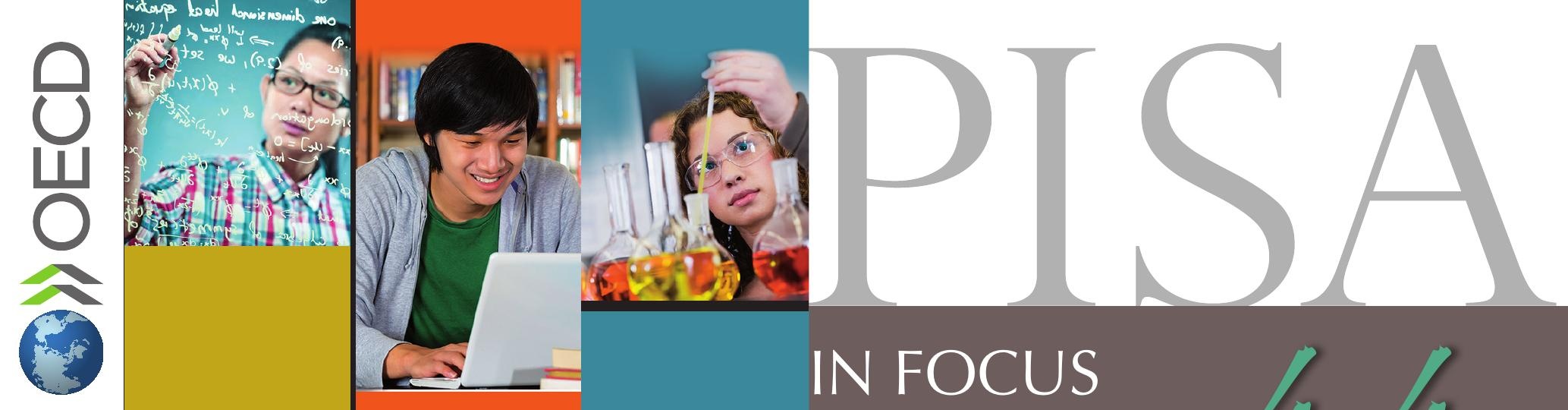

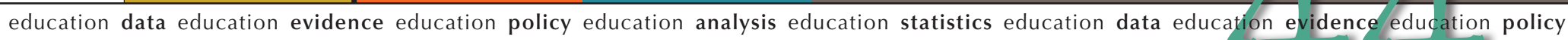

\title{
How is equity in resource allocation related to student performance?
}

- How educational resources are allocated is just as important as the amount of resources available.

- High-performing countries and economies tend to allocate resources more equitably across socio-economically advantaged and disadvantaged schools.

- Among the countries with better-resourced schools, as reported by principals, equity in resource allocation is not related to the overall quality of resources.

PISA has consistently found that the relationship between the amount of resources spent on education - including financial, human and material resources - is only weakly related to student performance. For example, among the PISA-participating countries and economies whose cumulative expenditure per student between the ages of 6 and 15 is below USD 50 000, the larger the amount spent, the higher the students' average score in mathematics. But among high-income countries and economies, including most OECD countries, other factors are better at predicting high scores in PISA. What this tells us is that, beyond a certain minimum level of expenditure per student, building an excellent education system requires something more than just money.

High-performing countries tend to allocate resources more equitably.
Fairness in resource allocation is not only important for ensuring equity in education opportunities, it is also related to the performance of the education system as a whole. High-performing countries and economies tend to allocate resources more equitably across all schools, regardless of their socio-economic profile. For example, Estonia, Finland, Germany, Korea and Slovenia all show higher-than-OECD-average performance in mathematics. In these countries, principals in disadvantaged schools tended to report that their schools had adequate educational resources as much as, if not more than, principals in advantaged schools reported. 
But in many school systems, resources are not allocated equitably. On average across OECD countries, while disadvantaged schools tend to have smaller classes, they also tend to be more likely to suffer from teacher shortages, and shortages or inadequacy of educational materials and physical infrastructure, than advantaged schools. In general, schools with more socio-economically disadvantaged students tend to have lower-quality resources than schools with more advantaged students.

For example, in the United States, the OECD country with the second lowest equity in resource allocation after Mexico, 25\% of disadvantaged students attend schools whose principal reported that a shortage or inadequacy of science laboratory equipment hindered, to some extent or a lot, the school's capacity to provide instruction; by comparison, only $15 \%$ of advantaged students attend such schools. In New Zealand, 54\% of disadvantaged students attend schools with adequate Internet connectivity, according to principals' reports, while $74 \%$ of advantaged students do. In Luxembourg, $40 \%$ of disadvantaged students attend schools with inadequate library materials, according to the schools' principals, while only $22 \%$ of advantaged students do. These differences are even larger among Latin American countries, including the OECD countries Chile and Mexico. Fewer than one in two disadvantaged students, but more than three in four advantaged students, in Mexico attend schools with adequate instructional materials, such as textbooks. In Chile, $62 \%$ of disadvantaged students and $88 \%$ of their advantaged peers attend schools where learning is not hindered by a lack of adequate instructional materials.

\section{Students perform better when school systems allocate resources more equitably}

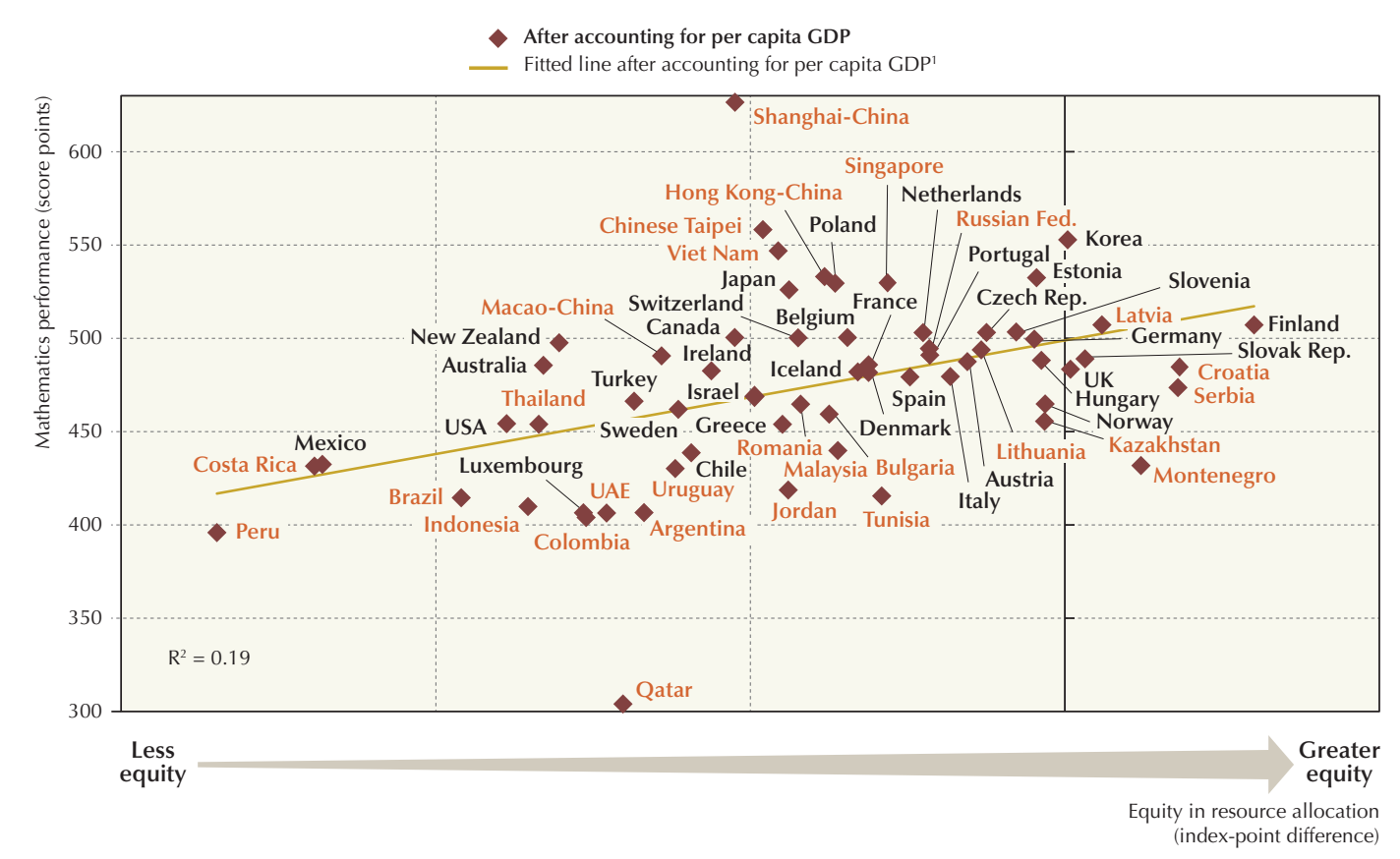

Note: Equity in resource allocation refers to the difference in the index of quality of schools' educational resources between socio-economically advantaged and disadvantaged schools.

1. A significant relationship $(\mathrm{p}<0.10)$ is shown by the solid line.

Source: OECD, PISA 2012 Database, Table IV.1.3.

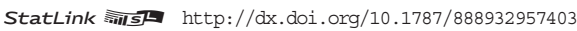



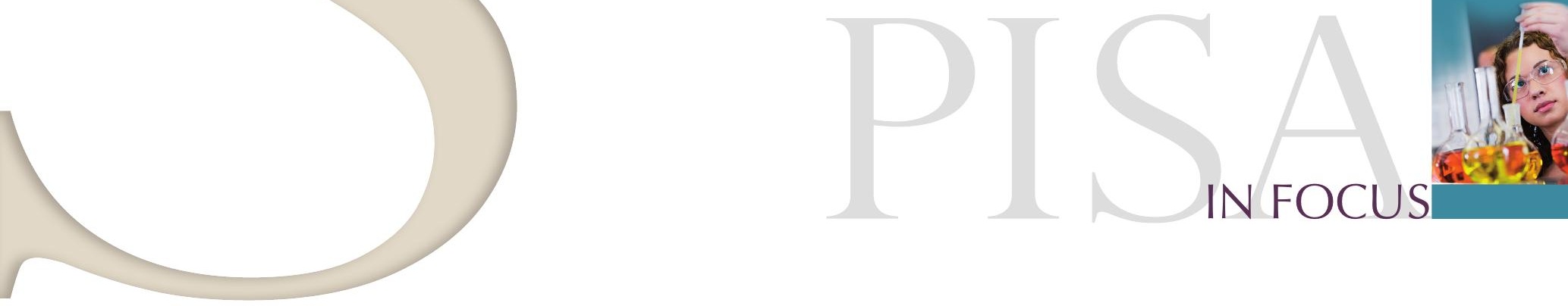

Not all students benefit from adequate resources

$\%$ of students in schools with adequate instructional materials $\begin{array}{lllllllllll}0 & 10 & 20 & 30 & 40 & 50 & 60 & 70 & 80 & 90 & 100\end{array}$

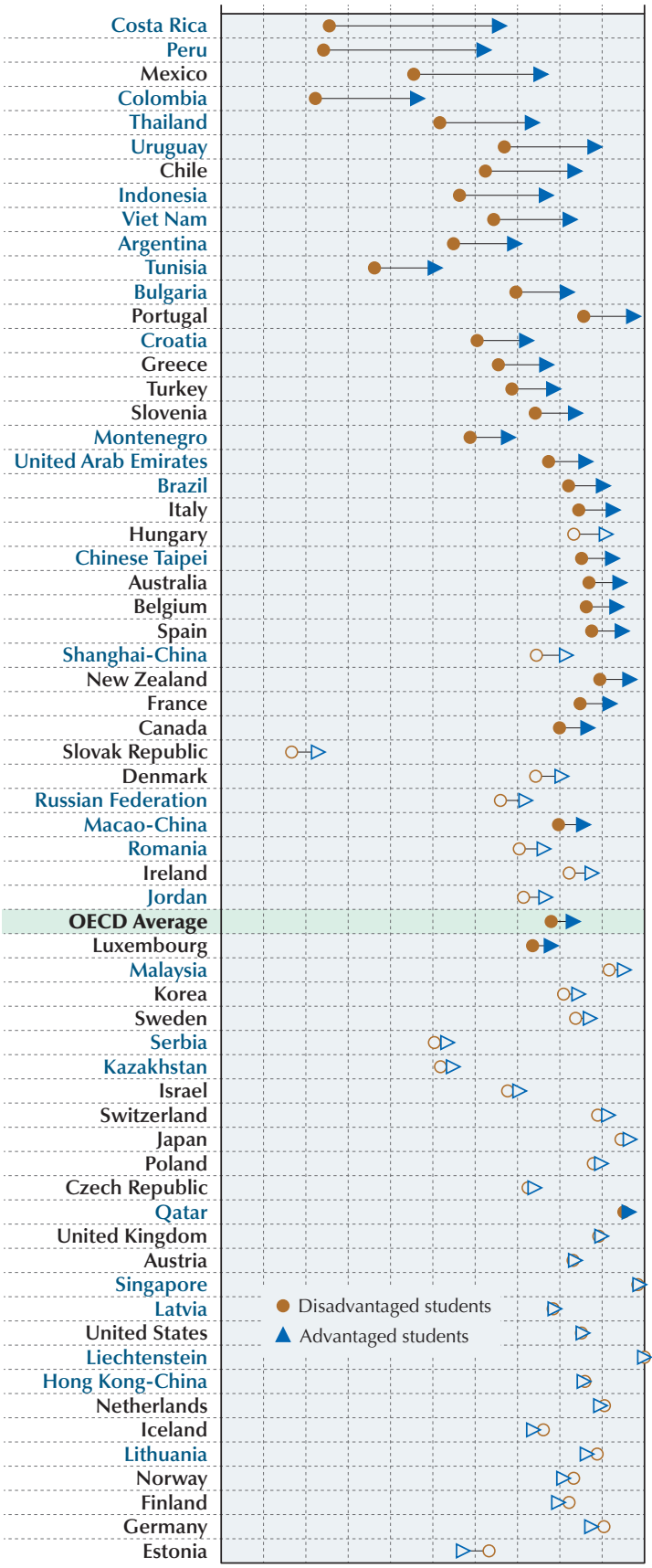

Note: The figure shows the proportion of students in schools whose principals reported that a shortage or inadequacy of instructional materials, such as textbooks, hindered their school's capacity to provide instruction "not at all" cx "very little". Countries a cho at or "very lin". Coun between advantaged and disadvantaged students. When the
In part, these stark differences can account for a large proportion of the overall differences in performance observed across countries, particularly among OECD countries. After accounting for per capita GDP, 19\% of the variation in mathematics performance across all countries and economies that participated in PISA 2012 can be explained by differences in principals' responses to questions about the adequacy of science laboratory equipment, instructional materials, such as textbooks, computers for instruction, Internet connectivity, computer software for instruction, and library materials. Among OECD countries, at least $30 \%$ of the variation in mathematics performance across countries can be explained by how equitably resources are allocated across all schools.

Too often, scarce educational resources are allocated inequitably.

In school systems where more students than average across OECD countries attend schools whose principals say that their educational resources are inadequate, those resources are less equitably distributed among advantaged and disadvantaged schools. In Mexico and the partner countries Costa Rica and Peru, a lack or inadequacy of resources hinders learning in many schools, particularly in socio-economically disadvantaged schools. These countries tend to allocate scarce resources to advantaged schools. By contrast, school principals in Finland tend to report that their schools enjoy a similar quality of resources regardless of how advantaged their schools are.

Among countries and economies where school principals report that a lack of educational resources hinders student learning less than is the case, on average, across OECD countries, equity in resource allocation is not necessary linked to the overall quality of resources; and the overall quality of educational resources is not related to systems' average performance, either. 
Of this group, the countries with the highest quality of educational resources, as reported by principals, including Australia, and the partner countries Singapore and Qatar, show very different levels of equity in the allocation of those resources, from high equity (Singapore) through moderate levels of equity (Qatar) to low equity (Australia).

\section{Better equity in resource allocation is not linked to higher-quality educational resources}

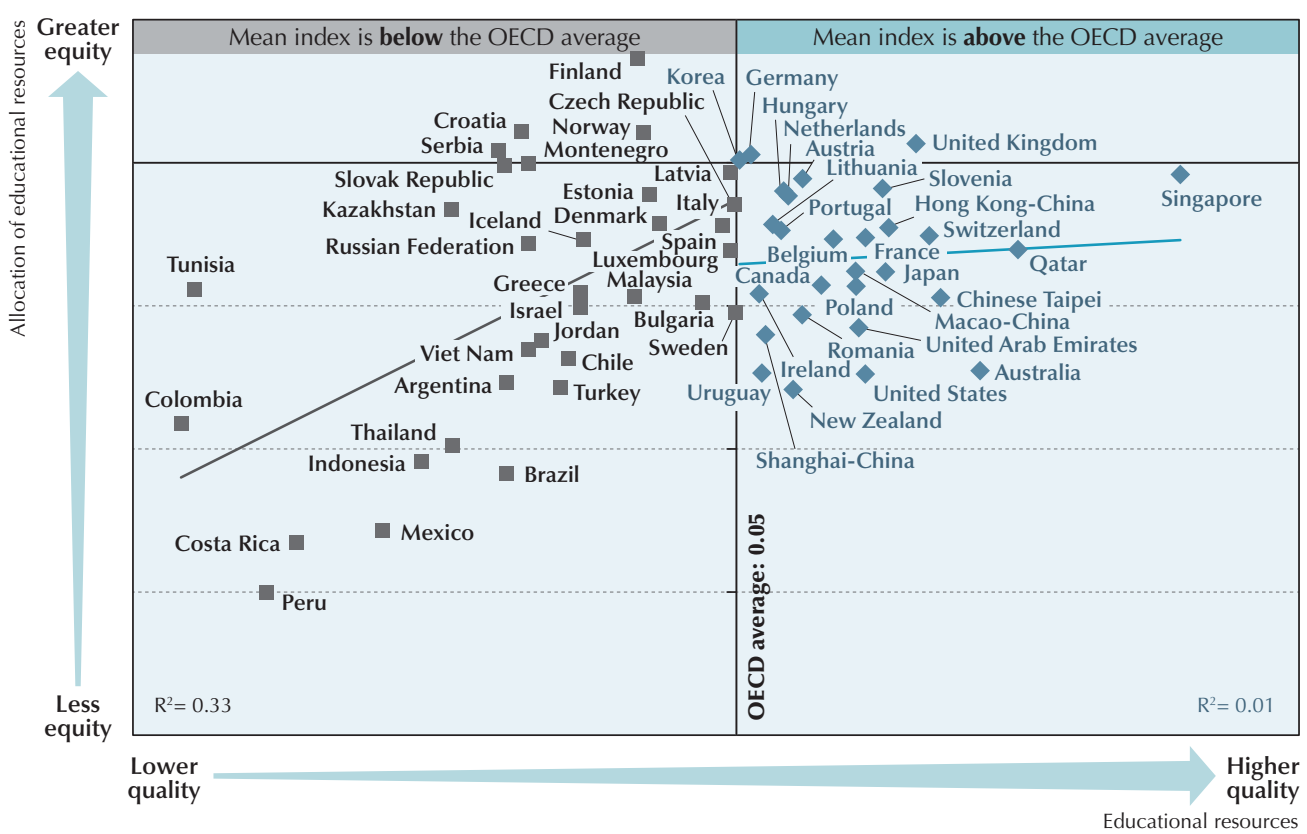

Notes: The vertical axis refers to the difference in the index of quality of schools' educational resources between socio-economically advantaged and disadvantaged schools (adv. - disadv.).

The horizontal axis refers to the mean index of quality of schools' educational resources.

Source: OECD, PISA 2012 Database, Tables IV.3.16 and IV.3.17.

StatLink त्ताज़ http://dx.doi.org/10.1787/888932957327

The bottom line: Higher-performing school systems allocate resources more equitably among socio-economically advantaged and disadvantaged schools. Supporting disadvantaged schools does not necessarily mean providing them with more resources, but rather with high-quality human and material resources.

\section{For more information}

Contact Pablo Zoido (pablo.zoido@oecd.org)

See OECD (2014), PISA 2012 Results: What Makes Schools Successful? Resources, Policies and Practices (Volume IV), PISA, OECD Publishing, Paris.

\section{Visit}

www.pisa.oecd.org

www.oecd.org/pisa/infocus

Education Indicators in Focus

Teaching in Focus

Coming next month

How well does performance in PISA predict young adults' skills proficiency?

Photo credit: @ khoa vu/Flickr/Getty Images @ Shutterstock/Kzenon @ Simon Jarratt/Corbis

This paper is published under the responsibility of the Secretary-General of the OECD. The opinions expressed and arguments employed herein do not necessarily reflect the official views of OECD member countries.

This document and any map included herein are without prejudice to the status of or sovereignty over any territory, to the delimitation of international frontiers and

boundaries and to the name of any territory, city or area.
The statistical data for Israel are supplied by and under the responsibility of the relevant Israeli authorities. The use of such data by the OECD is without prejudice to the status of the Golan Heights, East Jerusalem and Israeli settlements in the West Bank under the terms of international law. 